\title{
The Prime Ministerial Task Group on Emissions Trading
}

\section{Advocacy and Analysis}

\section{John Quiggin ${ }^{1}$}

The Report of the Prime Ministerial Task Group on Emissions Trading (2007) marks an important step in the development of the climate change debate in Australia. It is particularly notable for the evolution of views on the science of climate change, which reflects a change in the position of the Howard government, if not on the part of all of its members and supporters.

The position of the Intergovernmental Panel on Climate Change $(2001,2007)$ is supported by all the world's major scientific organisations (Australian Academy of Science et al. 2001). Although the Howard government has officially endorsed the mainstream scientific analysis of climate change, public statements by government ministers have regularly included explicit or coded support for the position referred to by its advocates as 'scepticism' on climate change (MacFarlane 2006, Minchin 2007).

This position entails either an implausibly massive outbreak of scientific incompetence or a deliberate fraud undertaken with the support of most of the world's scientists and scientific organisations. The claim of fraud has recently been presented by Evans (2006), and in the polemical film The Great Global Warming Swindle, endorsed by Minchin (2007).

In scientific terms, the 'sceptical' position has long since lost any credibility. But it has received strong public support in Australia from bodies such as the Lavoisier Group, and from a large number of commentators politically aligned with the government (a partial list includes Piers Akerman, Janet Albrechtsen, Andrew Bolt, Miranda Devine, Frank Devine, Jennifer Marohasy, P. P. McGuinness, Christopher Pearson and Alan Wood). Until recently at least, these views were influential in the business sector and in the Commonwealth bureaucracy (Hamilton 2007).

The Task Group report, produced by senior public servants and industry leaders, marks a welcome end to this stage in the debate. The science of global warming is taken as given, and the claims of the 'sceptics' are not even mentioned.

\footnotetext{
1 School of Economics, University of Queensland.
} 
Nevertheless, the outcome of the inquiry was tightly constrained by the political requirements of the government that commissioned it. Although a slender majority of the members of the committee were business leaders, the process was always going to be dominated by the senior public servants, including the chairman, whose participation reflected the government's need for tight control over the government.

On the one hand, it was virtually inevitable that the Group would recommend some form of emissions-trading scheme. Such an approach had been opposed by the government until just before the announcement of the inquiry. ABARE, the main public research agency in the field, had produced a string of reports supporting the view that technological change (implicitly assumed not to require any price incentive) would deliver more cost-effective reductions in emissions than any market-based approach (Ford et al. 2006, Fisher et al. 2006).

The abandonment of this view represented a return to Australia's (and ABARE's) earlier position in favour of market-based approaches, which was advocated with considerable success in the negotiations leading up to the agreement on the Kyoto Protocol. Although a number of European governments and non-government organisations favoured detailed regulation, Australia and the US successfully pushed for an approach based on tradeable permits.

Despite its rediscovery of the market, however, the government remained resolutely opposed to ratification of the Kyoto Protocol, even though, as the Report notes, Australia had played a significant role in the Kyoto negotiations, and even though, as the Report does not note, Australia had negotiated remarkably favourable emissions targets. Thus, unsurprisingly, the Report refers repeatedly, but mostly non-specifically, to the 'shortcomings' of Kyoto.

More problematically for the Group, the government remained uncomfortable with the idea of quantitative targets for emissions reductions. Since, any system of emissions-permit trading requires specification of the total volume of permits, the constraints under which the Group operated were potentially contradictory. Fortunately, and perhaps not coincidentally, John Howard announced, just before the Group's report was finalised, that he now accepted the general idea of targets.

In these circumstances it is necessary to consider the Report both as advocacy for the Howard government's position and as advice to the government on the best option to take, given its self-imposed political constraints. The Report does a better job on the second of these tasks than on the first.

\section{Advocacy}

The most notable section of the Report, considered as advocacy, was its discussion of possible targets for emissions reductions to be achieved by 2020 . The most ambitious target currently under discussion is that of the EU - that developed 
countries should commit to a reduction of 20 per cent relative to 1990 levels. Such a target for 2020 was also favourably mentioned by then Labor backbencher Peter Garrett in 2005, but without specifying a baseline.

The Report correctly observes that, given that Australia's emissions are currently about 8 per cent above the 1990 level and that the business-as-usual projection is for further growth of about 10 per cent, a cut of 20 per cent, relative to 1990 would require a 38 per cent reduction in emissions relative to business as usual.

By contrast, since the EU as a whole seems likely to meet its Kyoto target of a 6 per cent reduction relative to 1990 by 2012, the difficulty of achieving a further 14 per cent is not great. Moreover, the EU has an emissions-trading market and other necessary structures in place, while Australia has met its target exclusively by once-off measures to limit land clearing

In summary, the suggested target would indeed be ambitious for Australia. However, the Task Group stretches the truth to the limit when it says: "To illustrate the magnitude involved, this is equivalent to, for example, replacing Australia's entire existing fossil fuel-fired electricity generation capacity with electricity from nuclear energy while at the same time removing all existing vehicles from our roads." (p.35)

This claim was stressed in the press conference held to release the report. While literally correct, it is highly misleading. To see the problem, suppose that business-as-usual projections suggest a 100 per cent increase in emissions over some period, and that a proposed alternative target was to keep emissions unchanged. Then the effects of the required policy measures would be 'equivalent', in the sense used by the Task Group, to eliminating all existing use of fossil fuels.

Similarly, the fact that the cuts required to achieve a 20 per cent reduction may be 'equivalent' to drastic measures taken today does not mean that those measures are in fact required.

Among those apparently misled were journalists (Lewis and Shanahan 2007), and, more seriously, the Prime Minister, who had commissioned the report. Referring to the report, Mr Howard stated that 'Mr Garrett's proposal to cut emissions by 20 per cent of 1990 levels by the year 2020 could only be met by replacing every coal-fired and gas-fired power station with a nuclear plant and removing every car, truck and motorbike from the Australian roads.' (Marris 2007) Although the error in this claim was widely noted, and although the members of the Task Group would appear well-placed to advise the Prime Minister of the correct interpretation, it appears that no correction was ever issued. 


\section{Kyoto}

The other main piece of advocacy in the Report relates to the Kyoto Protocol and the international agreements that are likely to replace or succeed it. The criticisms of Kyoto offered in the Report are familiar (other countries are not meeting their targets, no reductions required from developed countries, and so on) and will not be discussed here.

As with the discussion of the 2020 target, the phrasing of these criticisms, while literally true, gives the misleading impression that Australia is set to meet its Kyoto target (on recent trends, this is unlikely) while nearly everyone else will miss theirs. This dubious claim is made more plausible by tricky language, excluding countries that purchase offsets through the Clean Development Mechanism, established under the Kyoto Protocol to permit developing countries to acquire and sell emissions credits for actions that offset emissions.

More important is the interaction, not discussed in the Report, between Australia's refusal to ratify the Kyoto Protocol and the difficulty we would face in meeting a 20 per cent reduction relative to 1990. As noted above, Australia's Kyoto targets were exceptionally generous.

Given the recommendation not to ratify Kyoto, the Report apparently envisages an international agreement that would not be based on Kyoto, and in which, presumably, the Kyoto targets would play no role. Since most international discussion is focused on the 1990 baseline for developed countries, it seems likely that any such agreement would set targets relative to that baseline, and there is no reason to suppose Australia's negotiating success at Kyoto would be repeated.

Hence, an agreement negotiated without reference to the Kyoto targets seems certain to be less favourable to Australia's interests than one that takes the Kyoto targets for 2012 as a starting point. The obvious way to avoid such an outcome is to ratify Kyoto and push the view that future agreements should take the 2012 Kyoto targets as the baseline.

The Report shows no recognition of any of this, or indeed of the international environment in which agreement will be reached. The Bush Administration, already in lame-duck mode, will be out of office in early 2009, and the EU, China and India have agreed to reach a post-Kyoto agreement by the end of that year. With a newly elected (most probably Democratic) Administration eager to rebuild some of the international capital squandered under Bush, US agreement to a global agreement based on the Kyoto process is quite probable.

Yet the Report is based on the assumption that US resistance to Kyoto, or anything based on Kyoto, will continue indefinitely. As evidence supporting this assumption, the Report quotes a 10-year-old non-binding Senate resolution, playing down more recent and relevant developments. 
The Report proposes a leisurely timetable in which Australia would determine its own short-term targets by 2010 and commence trading in 2011 or 2012. The justification is, in essence, that the inaction of the past decade makes it too costly to begin any earlier.

Appealing as this argument may be for domestic consumption, it is far less likely to appear credible in the context of international negotiations where Australia has long been seen as a spoiler. There is every risk that we will find ourselves presented with a fait accompli negotiated in our absence. In this context, it is notable that the Task Group fails to discuss the possible adverse consequences to Australia of failing to ratify Kyoto and staying outside the post-Kyoto process.

The possibility of imposing border taxes on imports from industrialised countries which refuse to commit to Kyoto after 2012 has already been raised by the French government. The EU trade commissioner, Peter Mandelson, rejected those calls (Mandelson 2007). However, his reasons for doing so, including the political undesirability of pursuing such penalties while a global consensus on post-2012 climate action is being negotiated, would be greatly weakened by a change in the current US position.

Of course, given a change in the US position, Australia would undoubtedly follow suit. But it would be hard to imagine a weaker position from which to enter negotiations than that being recommended by the Task Group.

\section{Analysis}

In considering the analysis of options presented by the Task Group, it is necessary to take as given the assumptions and political constraints discussed above. The most important of these assumptions is that the Kyoto process, including the negotiations scheduled for 2009, will fail to produce an agreement encompassing the major non-ratifying state, the United States, and the most important developing countries, China and India. Associated with this is the political constraint that Australia's strategy should not involve ratification of Kyoto or participation in the associated Clean Development Mechanism.

The first question to be addressed is whether, as was claimed when the AP6 group was established, it would be sufficient to rely on technological progress to achieve reductions in carbon emissions. Not surprisingly, this view, already undermined by the Switkowski report on nuclear power (Commonwealth of Australia 2006), was given short shrift. While the Group noted the benefits that could be gained from well-designed and targeted technology policies, it concluded: 'Given the magnitude of the abatement task facing Australia, it will be critical to rely on broader-based measures that are driven by the market.' (p.41) 
Given a primary reliance on market-based measures, the main choice is between carbon taxes, tradeable quota schemes and hybrids, such as those proposed by McKibbin and Wilcoxen (2002). This choice involves trade-offs regarding risk, efficiency and equity, as well as some complex political issues. The Task Group report discusses risk trade-offs associated with price and quantity targets and proposes a hybrid scheme in which a price cap for emissions would be set somewhat above the expected market-clearing price, given the goal for the period in question.

The crucial advantage of a tradeable quota scheme, relative to carbon taxes or price-capped schemes is that it allows for international trade in emissions. Conversely, the main appeal of price-capped hybrid schemes is that they address the concerns of interest groups averse to the risk associated with imposing a substantial price on carbon in the absence of a comprehensive international agreement. The Task Group's advocacy of a hybrid scheme is, therefore, a natural corollary of the assumptions and political constraints already discussed.

Assessment of the risk benefits of a hybrid scheme is difficult in the absence of any quantitative analysis or illustrative targets and quantities. In particular, it is important to distinguish between the technical risk that mitigating emissions will prove more costly than expected, and risk associated with variations in economic growth. In the latter case, a fixed emissions target serves as a countercyclical policy instrument, since the lower the growth in output, the lower the cost of meeting any given target.

\section{Concluding comments}

Australia has gone from leader to laggard in the international movement towards the use of internationally coordinated market-based policies to address the global problem of climate change. Having forgone the opportunity to make a significant contribution to shaping global policy agreements, we now run the risk of being forced to adopt policies negotiated in our absence.

Having relied on symbolic gestures and once-off measures for the decade since Kyoto, Australia will incur higher costs in the inevitable move to a global system of emissions trading than if we had moved earlier. Given the constraints under which it operated, the proposals put forward by the Task Group Report represent a reasonable compromise. Even given those constraints, however, the timetable proposed by the group is excessively long. The greater the delay in commencing the adoption of such a system, the greater will be the eventual costs.

By far the best solution to this problem would be to join the existing system created under the Kyoto Protocol, and work within the Kyoto process rather than against it. But of course, this option was ruled out in advance. 


\section{References}

Australian Academy of Sciences, Royal Flemish Academy of Belgium for Sciences and the Arts, Brazilian Academy of Sciences, Royal Society of Canada, Caribbean Academy of Sciences, Chinese Academy of Sciences, French Academy of Sciences, German Academy of Natural Scientists Leopoldina, Indian National Science Academy, Indonesian Academy of Sciences, Royal Irish Academy, Accademia Nazionale dei Lincei (Italy), Academy of Sciences Malaysia, Academy Council of the Royal Society of New Zealand, Royal Swedish Academy of Sciences, Turkish Academy of Sciences, and Royal Society (UK) 2001, 'The Science of Climate Change', Science, 18 May 2001, 292(5520), p.1261.

Commonwealth of Australia 2006, 'Uranium Mining, Processing and Nuclear Energy - Opportunities for Australia?' Report to the Prime Minister by the Uranium Mining, Processing and Nuclear Energy Review Taskforce.

Evans, R. 2006, 'Nine Lies about Global Warming', Lavoisier Group, 〈http://www.lavoisier.com.au/papers/articles/lav2006forWeb.pdf>

Fisher, B. et al. 2006, 'Technological development and economic growth', Inaugural Ministerial Meeting of the AP6, Sydney, 11-13 January. ABARE Research Report 06.1. Australian Bureau of Agricultural and Resource Economics, Canberra.

Ford, M., et al. 2006, 'Perspectives on international climate policy', paper presented at ABARE Conference Paper 06.3, presented to AARES Annual Conference, Sydney, February.

Hamilton, C. 2007, Scorcher: The Dirty Politics of Climate Change, Black Inc. Agenda, Melbourne.

Intergovernmental Panel on Climate Change 2001, 'Climate Change 2001: Working Group I: The Scientific Basis', IPCC, Geneva.

Intergovernmental Panel on Climate Change 2007, 'Working Group I Report (WGI): Climate Change 2007: The Physical Science Basis', IPCC, Geneva.

Lewis, S. and D. Shanahan 2007, 'Howard closes gap on climate', The Australian, 2 June 〈http://www.theaustralian.news.com.au/story/0,20867,21835049$601,00$. html >

MacFarlane, I. 2006, Interview on 'Sunday' program, http://sunday.ninemsn.com.au/sunday/political_transcripts/article_2053.asp

Mandelson, P. 2007, 'Energy Security and Climate Change — What Role for Trade Policy?', paper presented at Speech by Peter Mandelson, EU Trade Commissioner, delivered at a conference organised by Confederation of Norwegian Enterprise and EC Delegation in Norway at the Oslo Military 
Society in Oslo, Norway, 9 February 2007, «http://www.wbcsd.org/Plugins/DocSearch/details.asp?DocTypeId=35\&ObjectId $=$ MjI4NTg〉

Marris, S. 2007, 'PM warns of "Garrett recession"', The Australian, 4 June, 〈http://www.theaustralian.news.com.au/story/0,20867,21843798$601,00 . \mathrm{html}$ >

McKibbin, W. and P. Wilcoxen 2002, 'The role of economics in climate change policy', Journal of Economic Perspectives, 16(2), pp.107-29.

Minchin, N. 2007, Address to the National Press Club, Canberra, Q\&A session, 〈http://www.financeminister.gov.au/speeches/2007/sp_20070711_press_club_qa.html〉

Prime Ministerial Task Group on Emissions Trading 2007, 'Report of the Task Group on Emissions Trading', Department of the Prime Minister and Cabinet, Canberra. 